Research Article

\title{
Strength and Solidification Mechanism of Silt Solidified by Polyurethane
}

\author{
Fengyuan Li, ${ }^{1}$ Chaojie Wang $\mathbb{D}^{1},{ }^{1}$ Yangyang Xia, ${ }^{1}$ Yanjie Hao, ${ }^{1}$ Peng Zhao, ${ }^{1}$ \\ and Mingsheng Shi $\mathbb{1}^{1,2}$ \\ ${ }^{1}$ School of Water Science and Engineering, Zhengzhou University, Zhengzhou 450000, China \\ ${ }^{2}$ National and Local Joint Engineering Laboratory for Major Infrastructure Inspection and Repair Technology, Zhengzhou, \\ Henan, China \\ Correspondence should be addressed to Chaojie Wang; wangcjzzu@gs.zzu.edu.cn and Mingsheng Shi; sms315@126.com
}

Received 15 March 2020; Revised 14 August 2020; Accepted 23 August 2020; Published 18 September 2020

Academic Editor: Jia-wen Zhou

Copyright $(2020$ Fengyuan Li et al. This is an open access article distributed under the Creative Commons Attribution License, which permits unrestricted use, distribution, and reproduction in any medium, provided the original work is properly cited.

To determine the mechanism and strength characteristics of solidification of silt by a permeable polyurethane grouting material, the effects of polymer content, soil moisture, and immersion time on the unconfined compressive strength (UCS) of the silt have been studied. The results showed that the permeable polymer grouting material can significantly improve the performance of silt: (1) A higher amount of polymer produced a greater strength in the solidified soil. (2) The strength of the solidified soil increased as the immersion time was increased. (3) Moisture in the soil was not conducive to improving the strength of the solidified soil. The $\mathrm{X}$-ray diffraction (XRD) and energy-dispersive spectroscopy (EDS) have proven that polyurethane does not react with the silt, but they could improve the strength of the silt through physical action. Mercury intrusion porosimetry (MIP) and scanning electron microscopy (SEM) were performed to find that polymers can reduce soil porosity, and the addition of polyurethane improved the strength of the silt mainly through adhesion, wrapping, filling, and bridging.

\section{Introduction}

Due to river transportation, the low-liquid-limit silt is widely distributed in the middle and lower reaches of the Yellow River, Huaihe River, and Haihe River in China. Such silt is often used as roadbed filler in construction in these regions. The soil is, however, considered poor subgrade soil in the construction industry due to its high silt content, its poor water stability, and the difficulty to compact it. Consequently, developing silt solidification methods appears particularly important [1]. However, there are only a few studies on the solidification of silt and most of them use the soil curing agent to stabilize the clay. For example, Aiban et al. [2] proved the feasibility of stabilizing silt using cement and lime. Kolias et al. [3], Cheng et al. [4], and Rios et al. [5] stabilized clay and expansive soil with high-calcium fly ash, alkali-activated cement, and lime pozzolan, respectively, as the curing agent and explained the solidification mechanism from a microscopic perspective. However, the production of calcium-based inorganic substances like cement is very energy-consuming. Every ton of cement that is produced consumes $5000 \mathrm{MJ}$ of energy; most of this is produced from primary energy sources, such as coal. In addition to pollution such as dust, the production of cement also emits massive amounts of $\mathrm{CO}_{2}$ and $\mathrm{SO}_{2}$; these separately aggravate the greenhouse effect, produce acid rain, and cause serious pollution to the environment $[6,7]$. Many efforts have been made to develop green soil curing agents, and the most widely used ones currently include biological enzymatic curing agents, ionic curing agents, and organic polymer curing agents. Rafique et al. [8] introduced biological enzymes to reinforce silt roadbeds and evaluated the stabilization from the California Bearing Ratio (CBR) value. He et al. [9] and Junshuai Huo et al. [10] developed liquid ionic soil stabilizer (LISS) and EN-1 ionic soil curing agents to stabilize expansive soil and sandstone, respectively, and improved their UCS. Subsequently, Cai et al. [11] proposed a method to solidify soil with $\mathrm{MgO}$ and used it on the alluvial 
silt of the Yellow River. The UCS of the silt was 5.1 MPa after 28 days of curing, which was a significant improvement over other similar soil curing agents.

However, the performance of soil curing agents is often improved by extending the curing time, which is not compatible with emergency construction projects. As a result, organic polymer curing agents were developed for such applications [12]. Initially, Masoumi et al. [13] and Rezaeimalek et al. [14, 15] used polypropylene fibers, polyvinyl acetate resins, styrene-acrylic liquid polymers, and methylene diphenyl diisocyanate (MDI) to cure sandy soil, but the strength was still dependent on the curing time. Therefore, Liu et al. [16] proposed to solidify sand-clay mixtures with polyurethane polymers. The strength and the erosion resistance of the solidified soil were significantly improved due to the high early strength of polyurethane. Subsequently, Wei et al. [17] added sisal fiber to polyurethane to stabilize the sandy soil and investigated the strengthening mechanism from a microscopic perspective. Zhang et al. used lignin, a byproduct of the paper industry, to strengthen soil and studied the physical and mechanical properties of the stabilized soil [18]; the results showed that the byproduct lignin exhibited a satisfactory performance of improving engineering properties of both cohesive soils and noncohesive soils with respect to strength, erosion resistance, and durability [19]. They established a model to study the relationship between the energy required during the plane shear process and the external workload and proved the effectiveness of their solidified soil through field tests $[20,21]$.

Most of the current research on soil stabilization focuses on clay, sandy soil, and expansive soil, whereas the studies on silt remained scarce. Therefore, a soil curing agent based on a permeable polyurethane polymer to improve the stability of silt roadbeds was developed. It has a low viscosity and a high early strength. UCS tests were conducted along with a microscopic analysis to evaluate the solidification properties and discuss the solidification mechanism of the polymertreated silt. Our results provide a technical reference for the rapid and stable construction of roadbeds in silt-rich regions.

\section{Materials and Methods}

2.1. Test Materials. The polyurethane polymer used in the test was the $9802 \mathrm{~V}$ polymer produced by the Henan Road Inspection Engineering Technology Research Center. Figure 1 illustrates that the polymer is a two-component curing agent, where the main component of material $\mathrm{A}$ is polyol with a density of $1.26 \mathrm{~g} / \mathrm{cm}^{3}$, and the main component of material B is polymer isocyanate with a density of $1.17 \mathrm{~g} / \mathrm{cm}^{3}$. The material is mainly composed of $\mathrm{C}, \mathrm{H}, \mathrm{O}$, and N. Material A is mainly composed of hydrophilic low-viscosity polyether polyol, permeable diluent, and surfactant (nNCO-R-OCN); material B is mainly composed of isocyanate $((\mathrm{nHO} \sim \mathrm{OH})$. Both materials were mixed with a mass ratio of 1:1 to form a polyurethane polymer. The curing time of the polymer is controlled by a catalyst, and its curing time at normal temperature ranges from $10 \mathrm{~s}$ to $24 \mathrm{~h}$. In this study, the

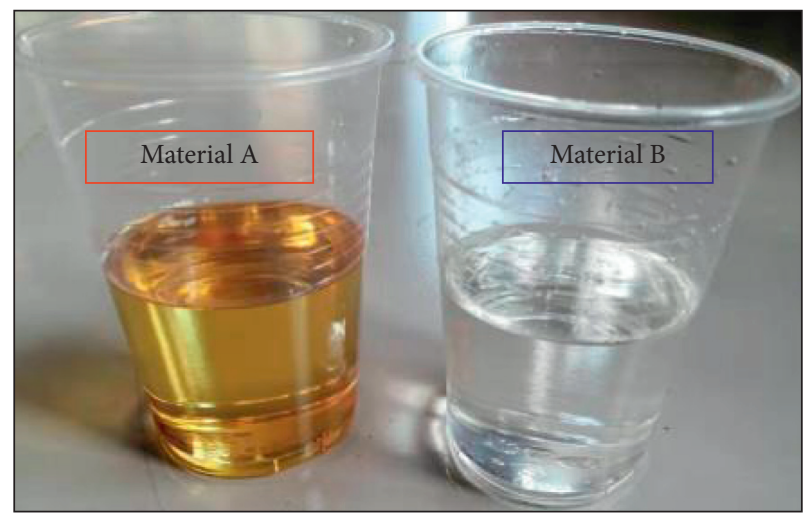

Figure 1: Materials A and B.

TAble 1: Physical properties of the soil used.

\begin{tabular}{lc}
\hline Specific gravity $G_{\mathrm{s}}$ & 2.70 \\
\hline Maximum dry density $\rho_{\mathrm{dmax}}\left(\mathrm{g} . \mathrm{cm}^{-3}\right)$ & 1.72 \\
Optimum moisture content $w_{\mathrm{op}}(\%)$ & 12.70 \\
Liquid limit $w_{\mathrm{L}}(\%)$ & 24.50 \\
Plastic limit $w_{\mathrm{P}}(\%)$ & 17.30 \\
Plasticity index $I_{\mathrm{P}}$ & 7.20 \\
\hline
\end{tabular}

curing time of the polymer was set to $6 \mathrm{~h}$. The mercury intrusion porosimetry (MIP) test was conducted by a mercury intrusion meter, namely, AutoPore IV 9500.

2.2. Preparation of the Specimens. The silt used in this test was taken from a depth of $5 \mathrm{~m}$ in a construction site in Zhengzhou. Table 1 shows the basic physical properties of the soil, and Figure 2 shows the distribution of the particle size of the soil. The soil used in this work was low-liquidlimit silt, as determined by accepted methods [22].

In addition, a mixing-compaction method was used to prepare the specimens. First, the plain soil was dried, broken, and filtered by a $2 \mathrm{~mm}$ sieve to obtain the test soil since the influence of particle gradation was ignored in this work. According to the preliminary test results, when the moisture content of the soil was less than $8 \%$ or the polymer content was more than $15 \%$, it was difficult to form the specimens. When the polymer content was less than $5 \%$ or the moisture content of the soil was more than $15 \%$, the distribution of the polymer in the soil was uneven, and the strength was only slightly higher than that of the specimens without the polymer. Soil samples were prepared with different moisture contents of $8 \%, 10 \%, 13 \%$, and $15 \%$; then different amounts of curing agent were added $(5 \%, 10 \%, 13 \%$, and $15 \%)$. Next, the curing agent containing materials $\mathrm{A}$ and $\mathrm{B}$ was mixed with a mass ratio of 1:1, and the product was added to the previously prepared soil samples with different moisture contents and mixed thoroughly. A triaxial compactor was used to prepare cylindrical specimens with a diameter of $39.1 \mathrm{~mm}$ and a height of $80 \mathrm{~mm}$ (Figure 3(a)). Three specimens were prepared for each set of parameters (moisture content, polymer content, and immersion time). Three specimens with the same parameters were prepared; a total 


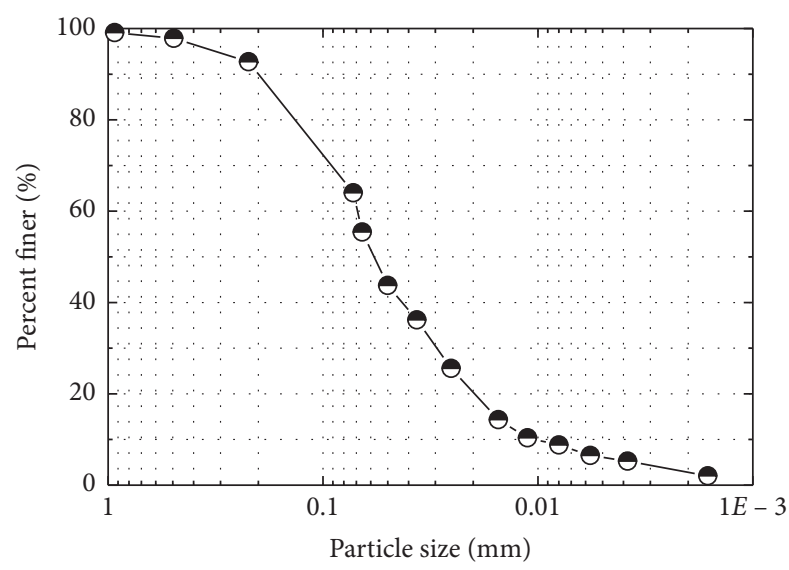

Figure 2: Particle size distribution in the materials tested.

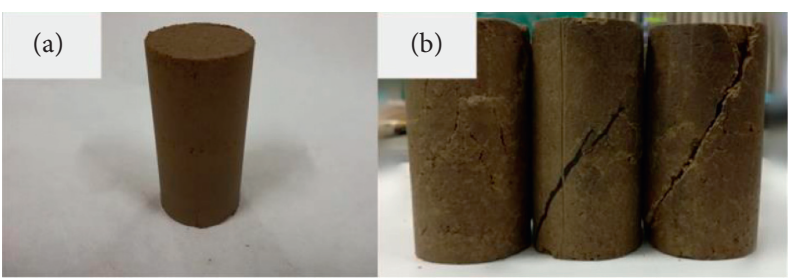

Figure 3: Specimens of solidified soil used for the study. (a) Sample before test. (b) Sample after test.

of 240 specimens were prepared and placed in a ventilated and dry place for $24 \mathrm{~h}$. The reaction was the self-reaction of the two materials, A and B, and it occurred relatively quickly. Unlike cement-based materials, there was no need for complicated maintenance conditions; the product will have a certain strength after being left to stand for $24 \mathrm{~h}$. And according to the results of the preliminary test, changing the curing conditions within 24 hours has little effect on its performance. This is also an advantage over other materials.

2.3. Test Method. To study the effect of the polymer on the solidification of the silt in a water environment, the specimens were immersed in water after standing for $24 \mathrm{~h}$. The UCS test was carried out on specimens immersed in water for $1,7,14,21$, and 28 days, as suggested in the standard method $[17,22]$. A TSZ-6 strain-controlled triaxial instrument (Figure 4) was used to perform the UCS test since the triaxial test is considered a UCS test when the confining pressure remains constant. At the same time, the strain rate was controlled at $0.5 \mathrm{~mm} / \mathrm{min}$ according to a standard method [22]. The maximum strength and the strength at a strain of $15 \%$ determined the unconfined compressive strength. Figure 3(b) shows the specimens after the test. Representative samples were taken for XRD and EDS analysis in order to study the interaction mode of the polymer and the silt. Finally, representative samples were scanned by electron microscope and tested by mercury injection to determine the microscopic mechanism of solidification of silty soil by polyurethane (Figure 5).

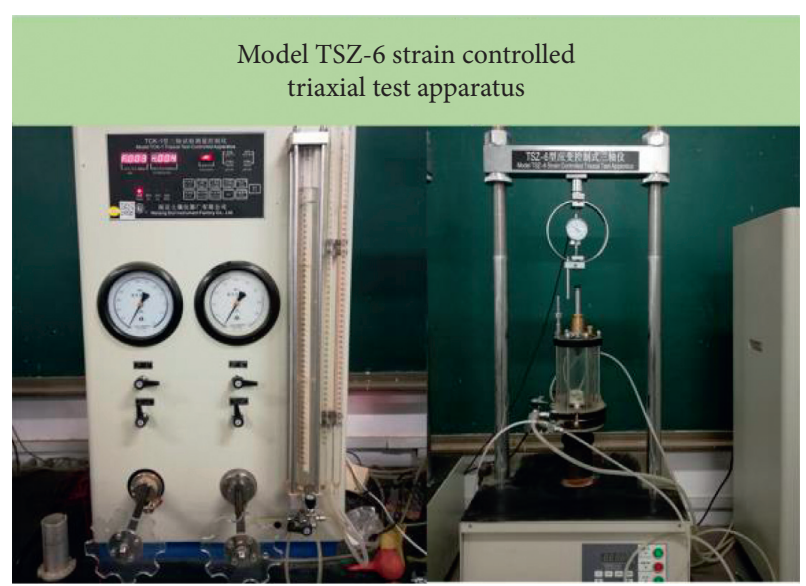

FIgURE 4: Model TSZ-6 strain controlled triaxial test apparatus.

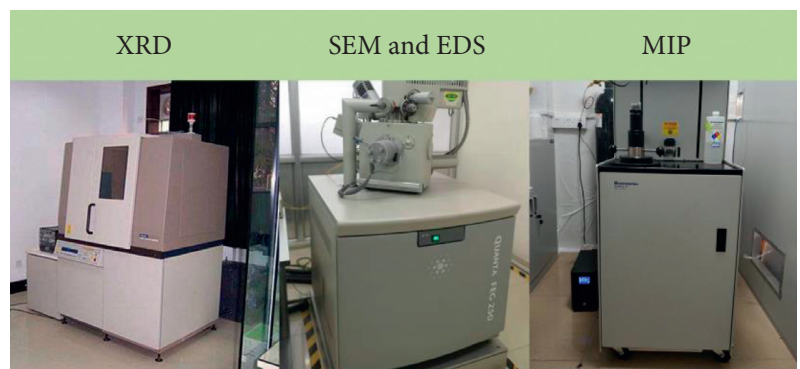

Figure 5: The XRD, EDS, SEM, and MIP instruments. 


\section{Results and Discussion}

3.1. Analysis of the UCS Test Results. To reduce measurement errors, three specimens for each set of parameters were tested in triplicate, and the specimen with a larger error was removed while the average value was reported. The UCS of the pure soil specimens with different moisture contents was also measured for direct comparison. Therefore, the following analysis uses a plain soil strength of $0.21 \mathrm{MPa}$ as a reference.

\subsubsection{Effect of Polymer Content on Strength of the Specimens.} Figure 6 shows the effect of polymer content on strength of the solidified soils. The results for specimens with a moisture content of $8 \%$ and an immersion time of 28 days are similar with those obtained by Liu et al. [16] and Wei et al. [17] and show that the polymer content has a significant impact on the strength of the solidified soil. The polymer amount is directly positively correlated with the UCS of the cured soil specimen. For example, when the polymer content is $5 \%$, the UCS is $0.47 \mathrm{MPa}$, but increases to $2.14 \mathrm{MPa}$ when the polymer content is $10 \%$. The strength increases by more than 3.5 times when the polymer doubles. When the polymer content increases from $13 \%$ to $15 \%$, the strength increases from $2.74 \mathrm{MPa}$ to $5.09 \mathrm{MPa}$. Compared with the specimen with a polymer content of $5 \%$, the strength increases by 4.8 times and 9.8 times when the polymer content increases by 1.6 times and 2.0 times, respectively. The strength also increases between 2.24 and 24.24 times compared with the plain soil specimen. This clearly indicates that the permeable polymer solidifies the silt used in this work.

3.1.2. Effect of Immersion Time on Strength of the Specimens. Figure 7 shows the effect of immersion time on the strength of solidified soil specimens with a moisture content of $8 \%$. The figure shows that UCS of solidified soil evolves linearly with the immersion time. Longer immersion times produced a higher UCS. Linear fit gives the linear relationship between the UCS and the immersion time for different polymer contents and indicates that the UCS is positively correlated with the immersion time. Compared with other cementbased soil curing agents, the permeable polymer developed in this study is more advantageous for the reinforcement of soil slopes in hydraulic engineering [23].

3.1.3. Effect of Soil Moisture Content on Strength of the Specimens. Figure 8 shows the effect of moisture content on the strength of solidified soil. For instance, the strength of specimen immersed in water for 28 days with a polymer content of $15 \%$ decrease when moisture content increases. When the moisture content increases from $8 \%$ to $10 \%$, the strength decreases by about $25 \%$. Similarly, when it increases from $10 \%$ to $13 \%$, the strength decreases by about $56 \%$. Finally, when it increases from $13 \%$ to $15 \%$, the strength decreases by about $8 \%$. However, for all specimens with a polymer content of $5 \%$, the decrease in strength is much less significant (between $2.2 \%$ and $6.3 \%$.) when the moisture

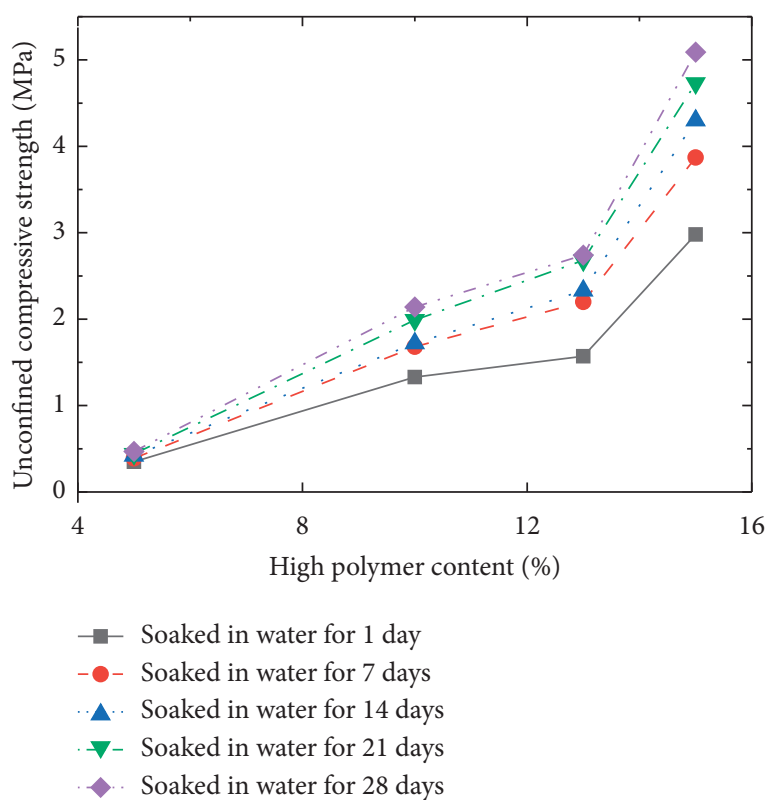

FIGURE 6: Effect of the polymer content on the strength of the solidified soil.

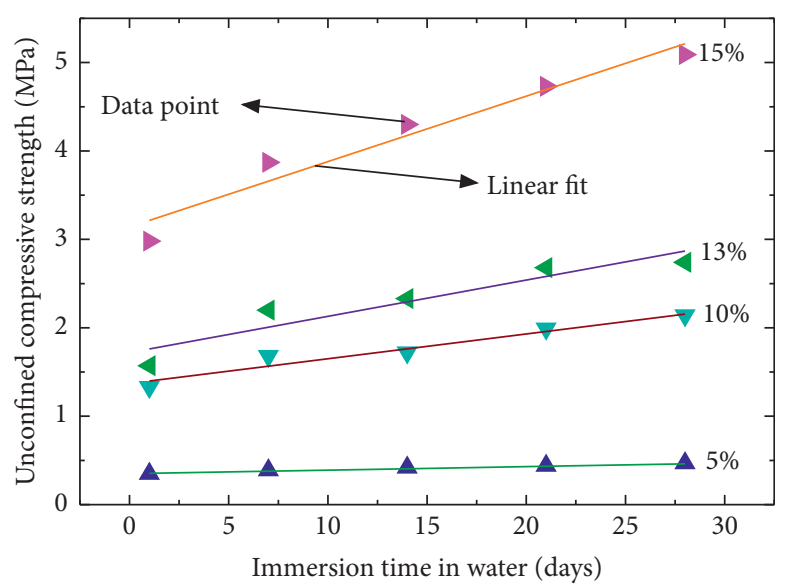

Figure 7: Effect of the immersion time on the strength of the solidified soil samples.

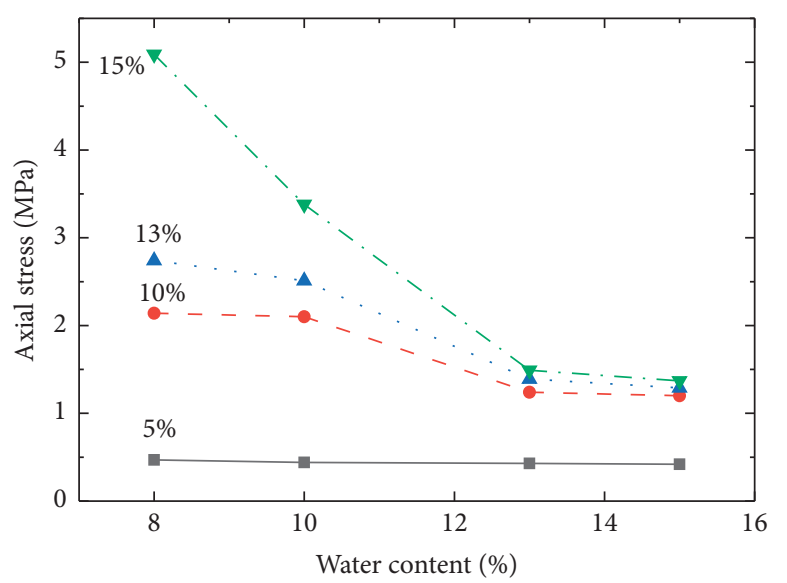

FIgURE 8: Effect of the moisture content on the strength of the solidified soil samples. 


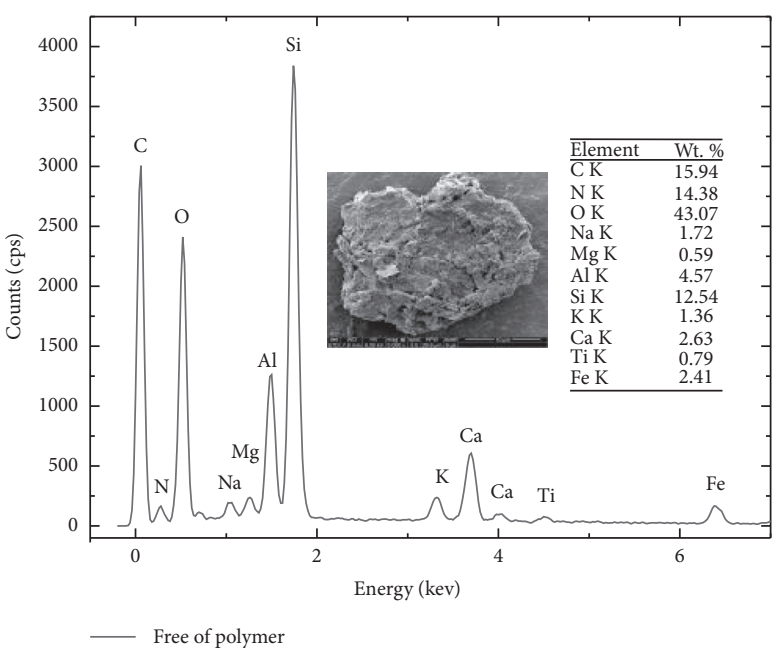

(a)

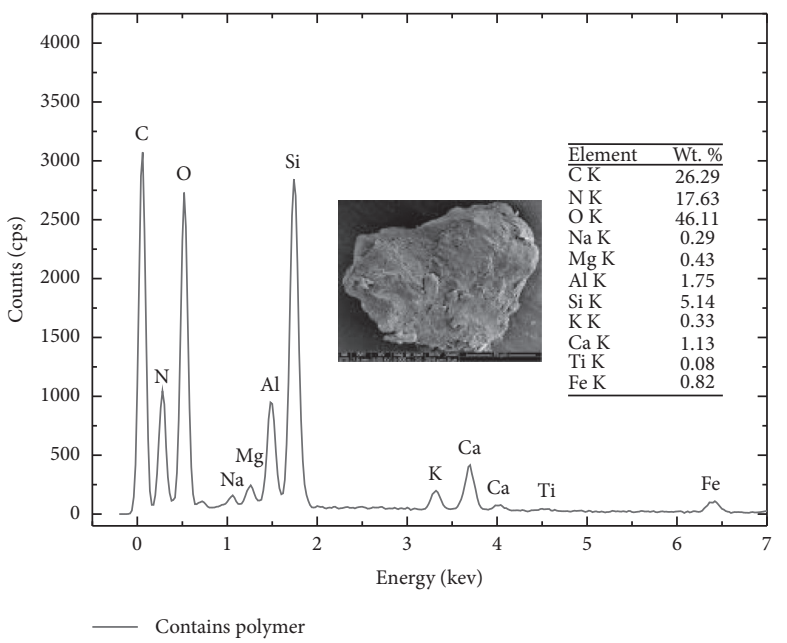

(b)

FIGURE 9: EDS energy spectrum of silt without and containing polymer.

content increases. It can be seen that soil with a high water content was not conducive to increasing the strength of the solidified soil [23].

3.2. Analysis of Mineral Composition of Solidified Soil. In order to explore the solidification mechanism of polymer and silt, XRD and EDS were used to analyze the chemical composition of solidified soil. It was investigated whether the strength of silt was increased due to the formation of new substances.

3.2.1. EDS Analysis. Comparing Figures 9(a) and 9(b), it can be seen that the $\mathrm{C}, \mathrm{N}$, and $\mathrm{O}$ content in the sample after the addition of the polymer had significantly increased, and the content of other elements was slightly reduced. This was because the polyurethane is a polymer compound with a large molecular weight. Both the isocyanate $(\mathrm{R}-\mathrm{N}=\mathrm{C}=\mathrm{O})$ and the polyol $(\mathrm{nHO} \sim \mathrm{OH})$ have a higher $\mathrm{C}, \mathrm{N}$, and $\mathrm{O}$ content; these three elements account for the increase in the ratio, and this indicates that the polymer has effectively adhered to the surface of the silt particles [24].

3.2.2. XRD Analysis. As shown in Figure 10, before and after the addition of the polymer, the diffraction spectra of the samples were basically the same, but the diffraction intensity fluctuated slightly; however, no new diffraction peaks appeared. This shows that after the polymer was added to the silt, the mineral composition of the soil did not change after solidification, and no new phase substances were formed. From this, it could be judged that only a physical interaction between the silt and the polymer occurred [23].

Based on the results of EDS and XRD, the polymer did not react with the silt, and it was effectively attached to the surface of soil particles.

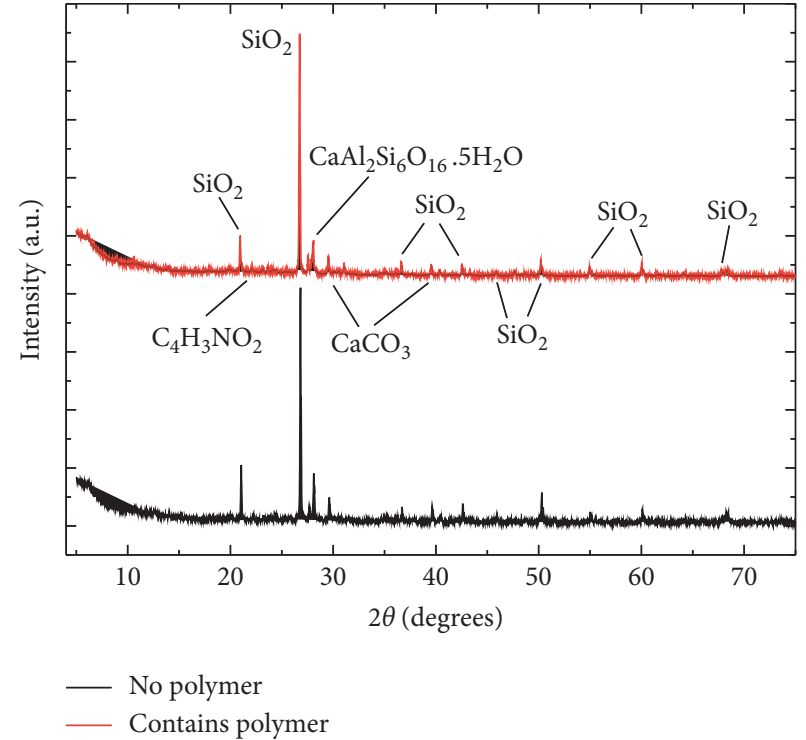

FIgURE 10: XRD diagram.

3.3. SEM Analysis. In order to further explore the solidification mechanism induced by polymer in silty soil, a scanning electron microscope (SEM) was used to image the soil samples.

3.3.1. Effect of Moisture Content on Strength of the Specimens. A series of samples with a polymer content of $15 \%$ were taken as representative examples to explore the effect of the water content of the silt on the strength of the solidified soil. Figure 11 shows the SEM images of the specimens with a polymer content of $15 \%$ and a moisture content of $8 \%, 10 \%$, $13 \%$, and $15 \%$, at a $100 \mu \mathrm{m}$ scale. The sheet-like film part appearing in the images is the polymer. The specimen with a moisture content of $8 \%$ has very smaller pores between the soil particles and the polymer fills almost all the voids between them. The polymer has a strong adhesion and forms a 

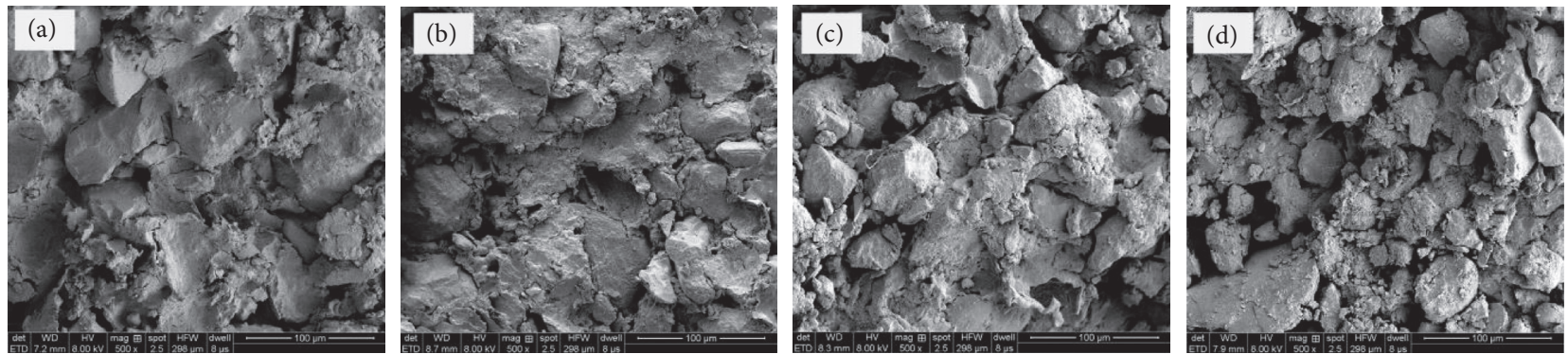

FIGURE 11: SEM images of the specimens with a polymer content of $15 \%$ and a moisture content of (a) $8 \%$, (b) $10 \%$, (c) $13 \%$, and (d) $15 \%$.
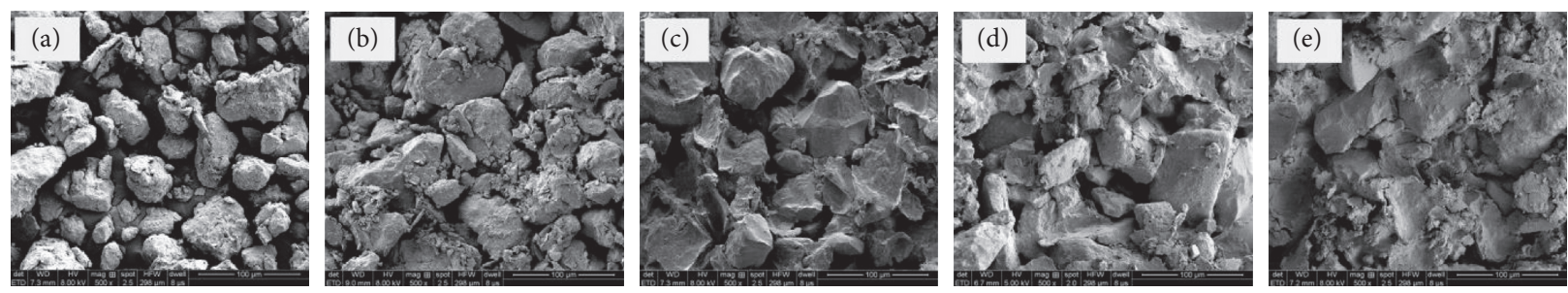

Figure 12: SEM images of the specimens with a moisture content of $8 \%$ and a polymer content of (a) $0 \%$, (b) $5 \%$, (c) $10 \%$, (d) $13 \%$, and (e) $15 \%$.
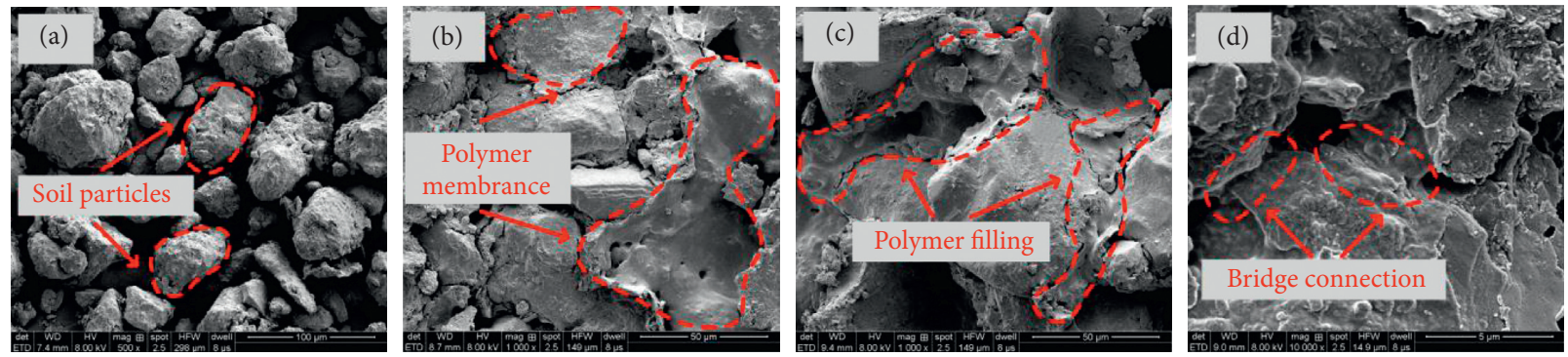

FIgURE 13: SEM images of the specimens (a) without polymer and (b, c, and d) with polymer.

dense film impermeable to water. The specimen with a moisture content of $15 \%$ has a loose soil particle distribution and the soil particles are not well bonded by the polymer. This is mainly because the soil specimens with a lower moisture content have less free water in the voids between the soil particles, and the polymer easily enters the pores to achieve a good filling. In the soil specimens with a high moisture content, only a small number of polymer molecules displace the free water to fill the pores and the excess of free water reduces the ability of the polymer to "wrap" soil particles, which reduces the adhesion to soil particles [25]. The presence of water affects the ability of polymer to fill voids within soil particles, hinders its adhesion performance, and prevents interconnections between soil particles. These negative effects are more pronounced when the moisture content increases.

3.3.2. Effect of Polymer Content on Strength of the Specimens. A series of samples with a water content of $8 \%$ were taken as representative to explore the effect of the polymer content on strength of solidified soil. Figure 12 shows SEM images of the specimens with a moisture content of $8 \%$ and a polymer content of $5 \%, 10 \%, 13 \%$, and $15 \%$, with a $100 \mu \mathrm{m}$ scale. The angular objects are soil particles. The specimen with a polymer content of $5 \%$ has a more dispersed distribution of soil particles that are not connected into large sheets and are separated by large voids. The soil particles in the specimen with a polymer content of $15 \%$ are well connected and almost form large sheets. The polymer is able to fill the voids between them. In soils with the same moisture content, a higher polymer content results in a stronger connection between the soil particles, which improves the compressive strength of the soil. This result is consistent with the UCS tests.

3.3.3. Microscopic Mechanism of Silt Solidification Induced by the Polymer. Our results allow us to propose a mechanism for the silt solidification by the polymer. Figure 13(a) shows the SEM image of the specimen with a moisture content of $8 \%$ but without any polymer. The soil particles in the specimen are loosely distributed, the voids are relatively large, and the soil particles compress and deform under the action of external forces. Figures 13(b) and 13(c) are the SEM images of the specimens with polymer. Since the 


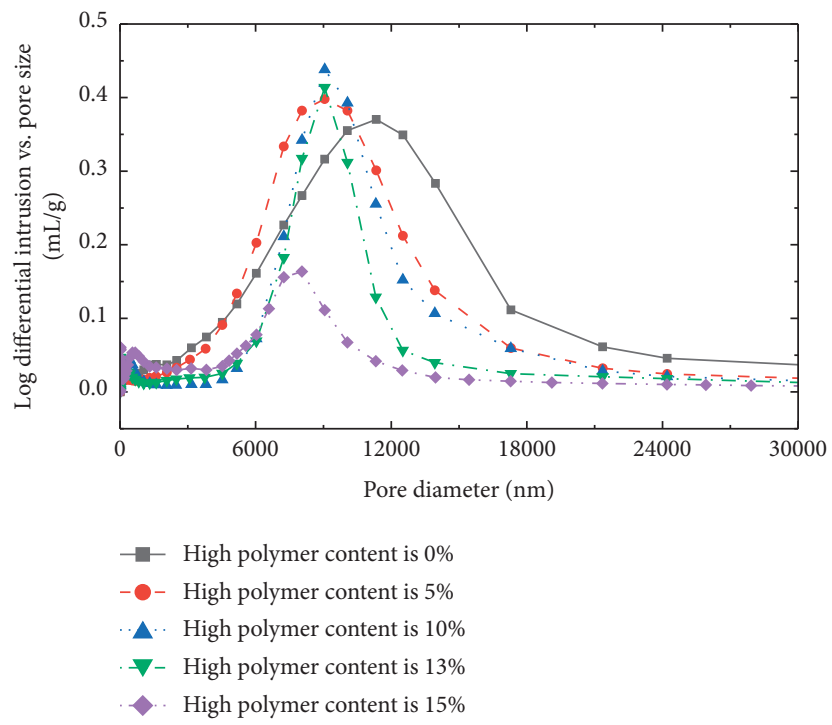

FIGURE 14: Distribution of the pore diameter.

TABLE 2: Physical properties of the specimens with a different polymer content.

\begin{tabular}{lccc}
\hline Polymer content & Porosity $(\%)$ & Packing density $(\mathrm{g} / \mathrm{ml})$ & Permeability $(\mathrm{md})$ \\
\hline Plain soil & 46.51 & 1.49 & 166.92 \\
$0 \%$ & 39.25 & 1.56 & 124.78 \\
$5 \%$ & 34.44 & 1.62 & 83.04 \\
$10 \%$ & 31.31 & 1.62 & 87.30 \\
$13 \%$ & 26.54 & 1.71 & 69.66 \\
$15 \%$ & 26.15 & 1.77 & 30.17 \\
\hline
\end{tabular}

polymer has a high "permeability," it fully penetrates into the voids between the soil particles, fills them, and "wraps" them. In short, the solidification by the polymer has two roles in the soil. Figure 13(b) shows that the polymer "covers" and "wraps" the soil particles to interconnect the particles and form sheets with a large area. The soil particles stick together to form a water-impermeable and air-impermeable "film." The presence of the film reduces the erosion of the strength of the specimen by water. The second role is illustrated in Figures 13(c) and 13(d): the polymer fills the voids between adjacent soil particles, forming a "bridge connection," making them stick with each other and thereby increase the density of the soil. Both actions by the polymer increased the ability of the soil particles to connect with each other; therefore, the permeability of the soil decreased; water affects the strength of the soil in a much reduced manner, and the compactness of the soil increases. As a result, the strength of the soil is significantly improved $[17,26]$.

3.4. Analysis by MIP. The SEM results show that the polymer has a filling effect between the soil particles. To study the void characteristics of the polymer-solidified soil, MIP was carried out on the specimens with a moisture content of $8 \%$ and different polymer contents. Figure 14 shows the corresponding pore distribution, and Table 2 lists the other physical characteristics of the specimens obtained by MIP. When the polymer content increases, the intermediate pore diameter, the pore diameter, and the total pore volume all gradually decrease. A higher polymer content densifies the soil. The decrease in the permeability also supports this conclusion [27]. The packing density in Table 2 shows that the specimen with a polymer content of $15 \%$ piles up more easily and becomes denser. The decrease of the porosity and the significant decrease of the permeability also show that the soil becomes denser when the polymer content increases. The results show that the solidification of the soil by the polymer effectively reduces the permeability of the soil and significantly increases its strength [28].

\section{Conclusions}

The purpose of this study was to illustrate the effect of the addition of polyurethane to soil. Based on the test results, polyurethane grouting material can be used as a soil curing agent, and it has been shown to have a significant curing effect on the silt.

The results showed that the addition of a higher amount of the polymer increased the strength of the solidified soil. Additionally, the strength of the solidified soil increased with the increase of the immersion time. However, a higher water content was not conducive to improving the strength of the solidified soil. Based on the result of the UCS and MIP, silt with an $8 \%$ water content mixed with $15 \%$ polymer can be regarded as the optimum concentration for yielding effective stabilization. 
According to the results from EDS and XRD, the principle action of the polyurethane-cured silt was not that it reacts chemically with silt, but that it improved the soil through physical actions. It can be seen that the polyurethane mainly improved the strength of the silt through adhesion, wrapping, filling, and bridging.

\section{Data Availability}

The data used to support the findings of this study are available from the corresponding author upon request.

\section{Conflicts of Interest}

The authors declare that they have no conflicts of interest regarding the publication of this paper.

\section{Acknowledgments}

This work was supported by the National Key R\&D Program of China (no. 2017YFC0405002) and the National Natural Science Foundation of China (NSFC) (no. 51679219).

\section{References}

[1] Z.-D. Zhu and S.-Y. Liu, "Utilization of a new soil stabilizer for silt subgrade," Engineering Geology, vol. 97, no. 3-4, pp. 192-198, 2008.

[2] S. A. Aiban, H. I. Al-Abdul Wahhab, O. S. B. Al-Amoudi, and H. R. Ahmed, "Performance of a stabilized marl base: a case study," Construction and Building Materials, vol. 12, no. 6-7, pp. 329-340, 1998.

[3] S. Kolias, V. Kasselouri-Rigopoulou, and A. Karahalios, "Stabilisation of clayey soils with high calcium fly ash and cement," Cement and Concrete Composites, vol. 27, no. 2, pp. 301-313, 2005.

[4] Y. Cheng, S. Wang, J. Li, X. Huang, C. Li, and J. Wu, "Engineering and mineralogical properties of stabilized expansive soil compositing lime and natural pozzolans," Construction and Building Materials, vol. 187, pp. 1031-1038, 2018.

[5] S. Rios, C. Ramos, A. Viana da Fonseca, N. Cruz, and C. Rodrigues, "Mechanical and durability properties of a soil stabilised with an alkali-activated cement," European Journal of Environmental and Civil Engineering, vol. 23, no. 2, pp. 245-267, 2019.

[6] F. G. Bell, "Lime stabilization of clay minerals and soils," Engineering Geology, vol. 42, no. 4, pp. 223-237, 1996.

[7] D. D. Higgins, "Briefing: GGBS and sustainability," Proceedings of the Institution of Civil Engineers-Construction Materials, vol. 160, no. 3, pp. 99-101, 2007.

[8] U. Rafique, S. Nasreen, R. Naveed, and M. A. Ashraf, “Application of bioenzymatic soil stabilization in comparison to macadam in the construction of transport infrastructure," Journal of Environmental Biology, vol. 37, no. 5 Spec No, p. 1209, 2016.

[9] S. He, X. Yu, A. Banerjee, and A. J. Puppala, "Expansive soil treatment with liquid ionic soil stabilizer," Transportation Research Record: Journal of the Transportation Research Board, vol. 2672, no. 52, pp. 185-194, 2018.

[10] J. S. Huo, Y. J. Geng, and Z. Q. Yu, "Experimental study on the weathered red sandstone soil road performance stabilized with EN-1 soil stabilizer," Advanced Materials Research, vol. 255-260, pp. 3190-3194, 2011.
[11] G.-H. Cai, S.-Y. Liu, Y.-J. Du, D.-W. Zhang, and X. Zheng, "Strength and deformation characteristics of carbonated reactive magnesia treated silt soil," Journal of Central South University, vol. 22, no. 5, pp. 1859-1868, 2015.

[12] M. Zhang, H. Guo, T. El-Korchi, G. Zhang, and M. Tao, "Experimental feasibility study of geopolymer as the nextgeneration soil stabilizer," Construction and Building Materials, vol. 47, pp. 1468-1478, 2013.

[13] E. Masoumi, S. M. A. Forooshani, and F. A. Nian, "Problematic soft soil improvement with both polypropylene fiber and polyvinyl acetate resin," Geotechnical and Geological Engineering, vol. 31, no. 1, pp. 143-149, 2013.

[14] S. Rezaeimalek, J. Huang, and S. Bin-Shafique, "Performance evaluation for polymer-stabilized soils," Transportation Research Record: Journal of the Transportation Research Board, vol. 2657, no. 1, pp. 58-66, 2017.

[15] S. Rezaeimalek, J. Huang, and S. Bin-Shafique, "Evaluation of curing method and mix design of a moisture activated polymer for sand stabilization," Construction and Building Materials, vol. 146, pp. 210-220, 2017.

[16] J. Liu, B. Shi, K. Gu, H. Jiang, and H. I. Inyang, "Effect of polyurethane on the stability of sand-clay mixtures," Bulletin of Engineering Geology and the Environment, vol. 71, no. 3, pp. 537-544, 2012.

[17] J. Wei, F. Kong, J. Liu et al., "Effect of sisal fiber and polyurethane admixture on the strength and mechanical behavior of sand," Polymers, vol. 10, no. 10, p. 1121, 2018.

[18] T. Zhang, G. Cai, and S. Liu, "Application of lignin-stabilized silty soil in highway subgrade: a macroscale laboratory study," Journal of Materials in Civil Engineering, vol. 30, no. 4, Article ID 04018034, 2018.

[19] T. Zhang, S.-Y. Yang, and S. Y. Liu, "Application of biomass by-product lignin stabilized soils as sustainable Geomaterials: a review," Science of The Total Environment, vol. 728, Article ID 138830, 2020.

[20] T. Zhang, Y.-L. Yang, and S.-Y. Liu, "A shear model for solidified soils considering conservation of energy," Computers and Geotechnics, vol. 120, Article ID 103439, 2020.

[21] T. Zhang, S. G. Cai, and S. Liu, "Application of lignin-based by-product stabilized silty soil in highway subgrade: a field investigation," Journal of Cleaner Production, vol. 142, no. 4, pp. 4243-4257, 2017.

[22] The National Standards Compilation Group of People's Republic of China, JTGE40 -2007 Test Methods of Soils for Highway Engineering, Standards Press of China, Beijing, China, 2007.

[23] S. Pu, Z. Zhu, H. Wang, W. Song, and R. Wei, "Mechanical characteristics and water stability of silt solidified by incorporating lime, lime and cement mixture, and SEU-2 binder," Construction and Building Materials, vol. 214, pp. 111-120, 2019.

[24] H. E. Fa-guo, S. U. LüRan, H. Zhong et al., "Durability test and reinforced mechanism on adding $\mathrm{SH}$ materials into soil of archaeological sites," Rock and Soil Mechanics, vol. 40, pp. 1000-7598, 2019.

[25] D. Zhang, X. G. Yang, and Z. L. WangZhang, "Study on application effect of sand consolidating agent for the slope of highway subgrade in season frozen zone," Advances in Civil Engineering, vol. 2019, Article ID 3716153, 7 pages, 2019.

[26] Y. Zhu, X. Yu, L. Gao, J. Chen, and M. D. Cotugno, "Unconfined compressive strength of aqueous polymer-modified saline soil," International Journal of Polymer Science, vol. 2019, Article ID 9137069, 11 pages, 2019.

[27] Y. Liu, Q. M. Chang, J. Y. LiuWang, W. Zheng, Y. Bao, and I. Rocchi, "Use of Sulfur-Free Lignin as a novel soil additive: a 
multi-scale experimental investigation," Engineering Geology, vol. 269, p. 105551, 2020.

[28] L. Cao, S. Y. Liu, G. H. Cai et al., "Permeability properties of carbonated reactive MgO-stabilized soils," Yantu Gongcheng Xuebao/Chinese Journal of Geotechnical Engineering, vol. 40, no. 5, pp. 953-959, 2018. 